\title{
REGULADOR DE CRESCIMENTO E Trichoderma harzianum APLICADOS EM SEMENTES DE FEIJOEIRO CULTIVADO EM SUCESSÃO A CULTURAS DE COBERTURA ${ }^{1}$
}

\author{
Tatiely Gomes Bernardes², Pedro Marques da Silveira ${ }^{3}$, Marcos Antônio Machado Mesquita²
}

\section{ABSTRACT \\ GROWTH REGULATOR AND Trichoderma harzianum APPLIED TO COMMON BEAN SEEDS CULTIVATED IN SUCCESSION TO COVER CROPS}

The objective of this study was to evaluate the effect of growth regulator and Trichoderma harzianum in common bean, in succession to different cover crops. The experimental design consisted of split-plots, in randomized complete blocks, with four replications. For plots, the leguminous Cajanus cajan, Stylosanthes guianensis, and Crotalaria spectabilis, and the grasses Pennisetum glaucum, Panicum maximum, Brachiaria brizantha, B. brizantha associated with Zea mays, and Sorghum bicolor were used as cover crops. The subplot treatments were: control; $500 \mathrm{~mL}$ of growth regulator (GR); $1,250 \mathrm{~mL}$ of biological fungicide (BF); and $500 \mathrm{~mL}$ of GR plus $1,250 \mathrm{~mL}$ of $\mathrm{BF}$, in $100 \mathrm{~kg}$ of seeds. Eighty-four days after the cover crops cutting, the common bean cultivar BRS Valente was sown. The root rot severity caused by Rhizoctonia solani and Fusarium solani f. $s p$. Phaseoli, incidence of fusarium wilt, grain yield, one hundred grain weight, number of pods per plant, and number of grains per pod were evaluated for common bean. The treatments with biological fungicide and growth regulators applied via seeds did not show significant effect, in relation to the analyzed variables. The sorghum straw favored the increase of root rot severity and fusarium wilt in the common bean crop.

KEY-WORDS: Vegetable hormones; biocontrol; Phaseolus vulgaris L.; no-tillage system; Cerrado.

\section{INTRODUÇÃO}

O Brasil é o maior produtor mundial de feijão comum (Phaseolus vulgaris L.), sendo que a produção total, na safra 2007/2008, atingiu mais de 3,5 milhões de toneladas (Conab 2009). Entretanto, a produtividade média brasileira é baixa, com $915 \mathrm{~kg} \mathrm{ha}^{-1}$, valor muito aquém do potencial genético da cultura e que, de acordo com a cultivar, pode atingir até $4.000 \mathrm{~kg} \mathrm{ha}^{-1}$. Atualmente, devido

\section{RESUMO}

Avaliou-se o efeito de regulador de crescimento e Trichoderma harzianum, aplicados em sementes de feijoeiro irrigado, em sucessão a diferentes culturas de cobertura. $\mathrm{O}$ delineamento experimental consistiu de parcelas subdivididas, em blocos casualizados, com quatro repetições. Nas parcelas, foram utilizadas culturas de cobertura, como as leguminosas guandu, estilosantes e crotalária, e as gramíneas milheto, capim mombaça, braquiária e braquiária consorciada com milho e sorgo. Nas subparcelas, os tratamentos foram: testemunha; $500 \mathrm{~mL}$ de regulador de crescimento, em $100 \mathrm{~kg}$ de sementes; $1.250 \mathrm{~mL}$ de fungicida biológico, em $100 \mathrm{~kg}$ de sementes; e $500 \mathrm{~mL}$ de regulador de crescimento mais $1.250 \mathrm{~mL}$ de fungicida biológico, em $100 \mathrm{~kg}$ de sementes. Aos 84 dias após o corte das culturas de cobertura, foi semeado o feijoeiro, cultivar BRS Valente. Foram avaliados a severidade de podridão radicular causada por Rhizoctonia solani e Fusarium solani f. sp. phaseoli, incidência por murcha-defusário, estande, rendimento de grãos, massa de 100 grãos, número de vagens por planta e número de grãos por vagem do feijoeiro. Os tratamentos com fungicida biológico e regulador de crescimento não apresentaram efeito significativo, em relação às variáveis analisadas. A palhada de sorgo favoreceu o aumento das podridões radiculares e da murcha-de-fusário no feijoeiro.

PALAVRAS-CHAVE: Hormônios vegetais; controle biológico; Phaseolus vulgaris L.; sistema plantio direto; Cerrado.

à possibilidade de produção do feijoeiro em várias épocas do ano, principalmente pelo advento da irrigação por aspersão, outro perfil de produtores entrou na atividade, com um sistema produtivo mais tecnificado (Kluthcouski et al. 2007). Este fato tem motivado a profissionalização da produção de feijão e, consequentemente, o aumento da produtividade.

O feijoeiro comum destaca-se entre as principais culturas anuais adaptadas ao sistema plantio direto (SPD). Segundo Menezes (2002), o SPD

1. Trabalho recebido em abr./2009 e aceito para publicação em nov./2010 (nº registro: PAT 5878/ DOI: 10.5216/pat.v40i4.5878). 2. Universidade Federal de Goiás, Escola de Agronomia e Engenharia de Alimentos, Setor de Solos, Goiânia, GO, Brasil. E-mails: tatielygb@gmail.com, marcosmesquita@yahoo.com.br.

3. Embrapa Arroz e Feijão, Setor de Sistemas Agrícolas, Santo Antônio de Goiás, GO, Brasil. E-mail: pmarques@cnpaf.embrapa.br. 
revelou-se a melhor alternativa de manejo, conciliando a manutenção e, até mesmo, a elevação dos patamares de produtividade, com sustentabilidade dos recursos empregados. A palhada das plantas de cobertura, na superfície do solo, é o principal componente de sucesso do SPD no Cerrado. Vários trabalhos têm demonstrado que as produtividades de grãos do feijoeiro variam, em razão da cultura precedente, de $1.300 \mathrm{~kg} \mathrm{ha}^{-1}$ a $3.152 \mathrm{~kg} \mathrm{ha}^{-1}$ (Garcia et al. 2003, Silveira et al. 2005, Silva 2006, Toledo-Souza 2006).

A aplicação de produtos em tratamento de sementes, ou via foliar, também tem se tornado uma prática agrícola rotineira, destacando-se o uso de fungicidas, inseticidas, inoculantes, antibióticos e hormônios, dentre outros.

$\mathrm{O}$ uso de reguladores vegetais pode incrementar o crescimento e o desenvolvimento vegetal, estimulando a divisão celular, a diferenciação e o alongamento celular, podendo, também, aumentar a absorção e a utilização de água e nutrientes pelas plantas (Vieira \& Castro 2004). Denomina-se regulador do crescimento a substância sintética que produz efeitos similares ao hormônio. Segundo Hinojosa (2005), há cinco tipos de hormônios considerados hormônios clássicos: auxinas, giberelinas, citocininas, etileno e inibidores, que são sintetizados em diferentes lugares da planta.

De acordo com Vieira (2001), o uso do bioestimulante Stimulate ${ }^{\circledR}$ (ácido índolbutírico a 0,005\%; citocinina a $0,009 \%$; e ácido giberélico a $0,005 \%$ ), nas culturas de feijão, arroz e milho, apresentou efeitos positivos e significativos sobre a germinação de sementes e vigor de plântulas. Nestas culturas, cultivadas em rizotron (tubos de PVC, possuindo vidro comum na face frontal), foi observado que o bioestimulante promoveu alterações expressivas ao sistema radicular e efeitos significativos nas variáveis relacionadas com a produtividade, quando comparadas com sua ausência.

A máxima produção de massa seca de grãos por planta de feijoeiro foi de 35,9 g, atingida na concentração de 2,4 mL de Stimulate ${ }^{\circledR}$, que superou, em $35,8 \%$, o controle. Castro et al. (2005) observaram que Stimulate ${ }^{\circledR}$ incrementou a massa seca das raízes de feijoeiro, até a concentração de $10 \mathrm{~mL} \mathrm{~kg}^{-1}$ de semente. O bioestimulante também aumentou o número de vagens por planta, o número de grãos por vagem e a massa seca de grãos por planta, na concentração de $5 \mathrm{~mL} \mathrm{~kg}^{-1}$ de semente.
Dentre os principais fatores da baixa produtividade do feijoeiro, encontram-se as doenças causadas por patógenos que habitam o solo, que podem provocar prejuízos severos, chegando a até $100 \%$ de perda, na produtividade da cultura. Estas doenças constituem um complexo etiológico caracterizado pelas podridões e murchas, que causam perdas de estande e vigor das plantas, comprometendo, desta forma, a produtividade da cultura. Para seu controle, o tratamento químico torna-se indispensável no tratamento da semente. Em contraste, o tratamento biológico com micro-organismos benéficos, em tratamento de sementes, é muito pouco conhecido. Espécies de Trichoderma sp. são consideradas eficientes antagonistas contra uma série de fungos fitopatogênicos. De acordo com Melo (1998), a ação de Trichoderma sp. ocorre por meio da associação ou não dos mecanismos de parasitismo, antibiose e competição.

Resende et al. (2004) observaram que sementes de milho inoculadas com $T$. harzianum resultaram em plantas com maior acúmulo de matéria seca nas raízes. Estes mesmos autores salientam que os fungicidas $\operatorname{Captan}^{\circledR}$ e Maxim ${ }^{\circledR}$, na dosagem recomendada para sementes de milho, não causaram efeitos fungitóxicos para T. harzianum. Faria et al. (2003) constataram que o tratamento de sementes com T. harzianum, carboxin + thiram e carbendazin + thiram possibilitou melhores índices de germinação e emergência em algodão, resultando em plântulas mais vigorosas. Melo \& Faull (2000), visando a selecionar linhagens efetivas de Trichoderma sp. para o controle de $R$. solani, concluíram que o uso de Trichoderma sp. inibiu o crescimento do patógeno e reduziu a viabilidade dos escleródios, e que não houve interação com o patógeno, provavelmente devido à forte inibição causada pelos metabólitos, que impediu o contato entre os dois fungos, sendo eficiente no controle de $R$. solani.

Este trabalho teve como objetivo avaliar o efeito de regulador de crescimento e o controle biológico de fungos do solo, por meio de Trichoderma harzianum, visando a uma maior produtividade do feijoeiro irrigado, em sucessão a diferentes culturas de cobertura.

\section{MATERIAL E MÉTODOS}

O experimento foi conduzido de outubro de 2005 a setembro de 2006, na área experimental da Fazenda Capivara, pertencente à Embrapa Arroz e 
Feijão, no município de Santo Antônio de Goiás, GO (16 $28^{\prime} 00^{\prime \prime} \mathrm{S}, 49^{\circ} 17^{\prime} 00^{\prime \prime} \mathrm{W}$ e altitude de $\left.823 \mathrm{~m}\right)$. Segundo a classificação de Köppen, o clima é do tipo Aw, tropical de savana, megatérmico, com temperatura média anual do ar de $22,6^{\circ} \mathrm{C}$, e médias mínimas e máximas de $14,1^{\circ} \mathrm{C}$ e $31,3^{\circ} \mathrm{C}$, respectivamente. A perda média anual por evaporação, medida pelo tanque classe "A", é da ordem de $1.938 \mathrm{~mm}$ (Silva et al. 2004). O solo é classificado como Latossolo Vermelho distrófico, de textura argilosa $\left(580 \mathrm{~g} \mathrm{~kg}^{-1} \mathrm{de}\right.$ argila, $130 \mathrm{~g} \mathrm{~kg}^{-1}$ de silte e $290 \mathrm{~g} \mathrm{~kg}^{-1}$ de areia). A análise química do solo, na camada $0-20 \mathrm{~cm}$, apresentou os seguintes resultados analíticos: $\mathrm{pH}\left(\mathrm{H}_{2} \mathrm{O}\right)=5,6 ; \mathrm{Ca}=$ $1,91 \mathrm{cmol}_{\mathrm{c}} \mathrm{dm}^{-3} ; \mathrm{K}=0,31 \mathrm{cmol}_{\mathrm{c}} \mathrm{dm}^{-3} ; \mathrm{P}=34 \mathrm{mg} \mathrm{dm}^{-3}$; e matéria orgânica $=21 \mathrm{~g} \mathrm{dm}^{-3}$ (Toledo-Souza 2006). $\mathrm{Na}$ área experimental, cultivaram-se, desde 2002, oito espécies de plantas de cobertura do solo, no verão, e, em sucessão, feijão irrigado, no inverno.

Estudou-se o efeito do regulador de crescimento Stimulate ${ }^{\circledR}$ e o controle biológico de fungos do solo, por meio de Trichoderma harzianum, em feijoeiro, em sucessão a diferentes culturas de cobertura. Adotou-se o delineamento experimental em blocos ao acaso, em esquema de parcelas subdivididas, com quatro repetições. Os tratamentos na parcela consistiram dos restos culturais de três leguminosas e cinco gramíneas, sendo, estas, respectivamente: guandu-anão (Cajanus cajan L. Millisp); estilosantes (Stylosanthes guianensis Aublet Sw. var. vulgaris) cv. Campo Grande; crotalária (Crotalaria spectabilis Roth.); milheto (Pennisetum glaucum L. R. Br.) cv. BN-2; sorgo granífero (Sorghum bicolor L. Moench) cv. BR 304; capim mombaça (Panicum maximum Jacq) cv. Mombaça; braquiária (Brachiaria brizantha Hochst ex A. Rich. Stapf.) cv. Marandú; e milho (Zea mays L.) híbrido BRS 3003, em consórcio com braquiária (B. brizantha $\mathrm{cv}$. Marandú).

Nas subparcelas cultivadas com feijoeiro, os tratamentos foram: T1) testemunha (tratamento com água); T2) $500 \mathrm{~mL}$ de regulador de crescimento (RC), em $100 \mathrm{~kg}$ de sementes; T3) $1.250 \mathrm{~mL}$ de fungicida biológico (FB), em $100 \mathrm{~kg}$ de sementes; e T4) $500 \mathrm{~mL}$ de RC com mais $1.250 \mathrm{~mL} \mathrm{FB}$, em $100 \mathrm{~kg}$ de sementes. O regulador de crescimento utilizado foi à base de ácido indolbutírico (auxina) 0,005\%; cinetina (citocinina) 0,009\%; e ácido giberélico (giberelina) $0,005 \%$. O fungicida biológico é um produto à base de Trichoderma harzianum '1306' (109 esporos viáveis $\left.\mathrm{mL}^{-1}\right)$. A área de cada subparcela foi de $15 \mathrm{~m}^{2}$ (2,5 m x 6,0 m).
Em outubro de 2005, antecedendo a implantação das culturas de cobertura, efetuou-se a dessecação da área, com a utilização de glifosato, na dosagem de $1,92 \mathrm{~kg} \mathrm{ha}^{-1}$ i.a. A semeadura das culturas de cobertura foi realizada mecanicamente, em novembro de 2005. Foram usadas as seguintes quantidades de sementes: $20 \mathrm{~kg} \mathrm{ha}^{-1}$ de sementes de braquiária, capim mombaça e milho; $25 \mathrm{~kg} \mathrm{ha}^{-1}$ de sementes de guandu; $40 \mathrm{~kg} \mathrm{ha}^{-1}$ de sementes de milheto; $10 \mathrm{~kg} \mathrm{ha}^{-1}$ de sementes de sorgo; $1,4 \mathrm{~kg} \mathrm{ha}^{-1}$ de sementes de estilosantes; e $8 \mathrm{~kg} \mathrm{ha}^{-1}$ de sementes de crotalária. Os espaçamentos foram de $0,4 \mathrm{~m}$, para as culturas de braquiária, milheto, capim mombaça e estilosantes, e de $0,8 \mathrm{~m}$, para as culturas de milho (consórcio com braquiária), guandu, crotalária e sorgo. A adubação de semeadura foi de $400 \mathrm{~kg} \mathrm{ha}^{-1}$, da fórmula 04-3016 , para todas as culturas. Aos 50 dias após o plantio do milho e do estilosantes, foi realizada adubação de cobertura, com $30 \mathrm{~kg} \mathrm{ha}^{-1}$ de $\mathrm{N}$ (ureia).

Aos quatro meses após o plantio, em março de 2006, as culturas de cobertura foram cortadas, utilizando-se um triturador de palhada $\left(\operatorname{Triton}^{\circledR}\right)$, e os resíduos foram deixados na superfície do solo. A semeadura do feijoeiro comum foi realizada manualmente, em junho de 2006, 84 dias após o corte das coberturas. A cultivar utilizada foi a BRS Valente, pertencente ao grupo preto, arbustivo, de hábito de crescimento indeterminado (tipo II - com ramificações abertas). O espaçamento foi de $0,5 \mathrm{~m}$ entre linhas, utilizando-se de 17 a 18 sementes por metro, e estas foram colocadas a, aproximadamente, $5 \mathrm{~cm}$ de profundidade. A adubação de plantio foi realizada mecanicamente, durante a abertura dos sulcos para plantio, utilizando-se $400 \mathrm{~kg} \mathrm{ha}^{-1} \mathrm{da}$ fórmula 05-30-15.

No dia seguinte à semeadura, foi aplicado o herbicida paraquat, na dosagem de $0,2 \mathrm{~kg}$ i.a. ha ${ }^{-1}$. Foram efetuadas duas adubações de cobertura com ureia, aos 24 e 38 dias após a emergência, aplicando-se $32 \mathrm{~kg} \mathrm{ha}^{-1}$ e $40 \mathrm{~kg} \mathrm{ha}^{-1}$ de N, respectivamente. Aos 25 dias após a semeadura, foram aplicados os herbicidas fomesafen $\left(0,25 \mathrm{~kg}\right.$ i.a. ha $\left.{ }^{-1}\right)$ e fluazifop-p-butil $\left(0,188 \mathrm{~kg}\right.$ i.a. $\left.\mathrm{ha}^{-1}\right)$, e o inseticida tiametoxam $\left(0,025 \mathrm{~kg}\right.$ i.a. ha $\left.{ }^{-1}\right)$.

O método de irrigação utilizado foi aspersão em sistema pivô central e o manejo da irrigação foi realizado de acordo com as leituras obtidas em três baterias de tensiômetros instalados às profundidades de $15 \mathrm{~cm}$ e $30 \mathrm{~cm}$. As irrigações foram realizadas quando a média das leituras dos tensiômetros de decisão, 
instalados a $15 \mathrm{~cm}$ de profundidade, alcançavam entre $30 \mathrm{kPa}$ e $40 \mathrm{kPa}$.

Aos 26 dias após a semeadura do feijoeiro, foram removidas dez plantas ao acaso, nas linhas laterais, por subparcela. As plantas foram arrancadas com auxílio de um sacho, sem destruir o sistema radicular, e, posteriormente, foram acondicionadas em sacos plásticos. Em laboratório, as plantas foram lavadas e foi realizada a avaliação da severidade de podridão radicular, causada por $R$. solani e $F$. solani f. sp. phaseoli.

Para avaliação da severidade, foi utilizada a escala de notas a seguir: 1 = sem sintomas visíveis; $3=$ ligeira descoloração, sem lesões necróticas ou até $10 \%$ dos tecidos do hipocótilo e da raiz cobertos com lesões; 5 = aproximadamente $25 \%$ dos tecidos do hipocótilo e da raiz cobertos com lesões, mas com tecidos firmes e com pouca deterioração do sistema radicular; $7=$ aproximadamente $50 \%$ dos tecidos do hipocótilo e da raiz cobertos com lesões, que se combinam com amolecimento, podridão e redução consideráveis do sistema radicular; e $9=$ aproximadamente $75 \%$ dos tecidos do hipocótilo e da raiz afetados por estados avançados de podridão, em combinação com redução severa do sistema radicular (Schoonhoven \& Pastor-Corrales 1987). Para análise de variância, os dados foram transformados para raiz quadrada de $\mathrm{x}+1$.

Foi avaliado, aos 81 dias após a semeadura, o número de plantas murchas, com sintomas de murcha causada por Fusarium oxysporum f. sp. phaseoli. A incidência da murcha-de-fusário foi estimada com base em amostragem, em área de $2 \mathrm{~m}^{2}$ de cada parcela, e foram computados o número de plantas total e o número de plantas que apresentavam sintomas da doença. Para análise de variância, os dados foram transformados para raiz quadrada de $\mathrm{x}+1$.

Após a colheita do feijoeiro, foram avaliadas as seguintes variáveis: rendimento de grãos $\left(\mathrm{kg} \mathrm{ha}^{-1}\right)$, massa de 100 grãos (g), número de vagens por planta, número de grãos por vagem e estande inicial e final (número de plantas $\mathrm{m}^{-2}$ ). A umidade dos grãos foi corrigida para $13 \%$. Para a avaliação da massa de 100 grãos, número de vagem por planta e número de grãos por vagem, foram coletadas três plantas ao acaso, dentro da área útil. Aos 30 dias após a semeadura, foi avaliado o estande inicial (a área avaliada foi de $2 \mathrm{~m}^{-2}$ ) e o número de plantas finais (estande final) foi avaliado durante a colheita, na área útil, para rendimento de grãos.
Os dados foram submetidos a análise de variância (teste $\mathrm{F}$ ) e as médias comparadas pelo teste Tukey, a 5\% de probabilidade. Utilizou-se, para estas análises, o software Sisvar, versão 4.6 (Ferreira 2003).

\section{RESULTADOS E DISCUSSÃO}

A severidade da podridão radicular no feijoeiro, causada por $R$. solani e $F$. solani $\mathrm{f}$. sp. phaseoli, não foi influenciada, significativamente, pelos tratamentos com fungicida biológico e regulador de crescimento e, também, não foram detectadas diferenças significativas na interação entre estes tratamentos e as palhadas das culturas de cobertura, sendo, porém, significativas entre as culturas de cobertura.

Paula Júnior et al. (2009) verificaram que, com uma aplicação de Trichoderma spp., aos 10 ou 25 dias após a emergência do feijoeiro, não houve redução da incidência de mofo branco (Sclerotinia sclerotiorum) ou aumento no rendimento de grãos, quando comparados com a testemunha. Segundo estes autores, as condições ambientais, durante a realização dos experimentos, podem ter comprometido a eficácia de Trichoderma spp. no controle do mofo branco.

Quanto à influência das culturas de cobertura na severidade da podridão radicular, houve diferença significativa entre as palhadas de sorgo e mombaça e estas não diferiram das palhadas de milheto, guandu, estilosantes, braquiária com milho, crotálaria e braquiária (Tabela 1). A podridão radicular foi maior $(3,31)$ no feijoeiro em sucessão ao sorgo. Resultado semelhante foi constatado em experimento realizado por Lobo Júnior et al. (2005), em que a severidade da podridão radicular foi maior em feijoeiro precedido por sorgo, quando comparado com crotálaria, guandu, mucuna e pousio, em sistema orgânico de produção. A podridão radicular no feijoeiro foi menor $(2,45)$ no plantio em sucessão à palhada de mombaça.

A murcha-de-fusário, causada por Fusarium oxysporum f. sp. phaseoli, no feijoeiro, de acordo com a análise de variância, não foi influenciada, significativamente, pelos tratamentos com fungicida biológico, regulador de crescimento e palhadas das culturas de cobertura e, também, não foram detectadas diferenças significativas da interação entre estes tratamentos e as palhadas das culturas de cobertura.

Apesar de não terem sido observadas diferenças significativas entre as palhadas das culturas de cobertura, para controle da murcha-de-fusário, o 
Tabela 1. Severidade de podridão radicular (Rhizoctonia solani e Fusarium solani f. sp. phaseoli) e percentagem de incidência de plantas com sintomas de murcha-de-fusário (Fusarium oxysporum f. sp. phaseoli), em feijoeiro cv. BRS Valente, em sucessão a diferentes culturas de cobertura e tratado com regulador de crescimento (RC) e fungicida biológico (FB) (Santo Antônio de Goiás, GO, 2006).

\begin{tabular}{|c|c|c|}
\hline Tratamentos & Podridão radicular $^{1}$ & Murcha-de-fusário \\
\hline \multicolumn{3}{|c|}{ Coberturas vegetais } \\
\hline Braquiária consorciada & $2,66 a^{2,3}$ & $12,32^{3, \mathrm{~ns}}$ \\
\hline Braquiária solteira & $2,51 \mathrm{ab}$ & 7,03 \\
\hline Milheto & $3,12 \mathrm{ab}$ & 7,02 \\
\hline Mombaça & $2,45 \mathrm{a}$ & 10,56 \\
\hline Sorgo & $3,31 \mathrm{~b}$ & 22,06 \\
\hline Crotalária & $2,60 \mathrm{ab}$ & 14,24 \\
\hline Estilosantes & $2,86 \mathrm{ab}$ & 12,81 \\
\hline Guandu & $2,96 \mathrm{ab}$ & 15,57 \\
\hline \multicolumn{3}{|c|}{ Fungicidas/regulador crescimento } \\
\hline Testemunha & 2,91 & 13,74 \\
\hline Regulador crescimento (RC) & 2,82 & 12,37 \\
\hline Fungicida biológico (FB) & 2,71 & 12,32 \\
\hline $\mathrm{RC}+\mathrm{FB}$ & 2,80 & 12,37 \\
\hline C.V. a $(\%)$ & 30,00 & 58,00 \\
\hline C.V. b $(\%)$ & 18,20 & 26,90 \\
\hline
\end{tabular}

${ }^{1}$ Escala de notas: 1 - sem sintomas visíveis; 3 - até $10 \%$ dos tecidos do hipocótilo e da raiz cobertos com lesões; e 5 - aproximadamente $25 \%$ dos tecidos do hipocótilo e da raiz cobertos com lesões.

${ }^{2}$ Letras minúsculas iguais, na coluna, indicam que as médias não diferem entre si, pelo teste Tukey $(\mathrm{p}>0,05)$.

${ }^{3}$ Dados originais.

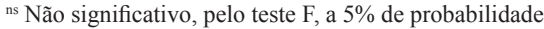

maior valor de incidência da doença foi no plantio do feijão em sucessão ao sorgo (22,06\%) (Tabela 1). Resultados semelhantes foram constatados por Toledo-Souza (2006), que, trabalhando com as mesmas culturas de cobertura, na mesma área experimental, observou diferenças significativas entre culturas antecedentes, obtendo maiores incidências desta doença, quando o feijoeiro foi precedido por sorgo (média de 47\%), nas safras 2003 e 2004. Segundo a autora, pressupõe-se que a baixa produção de massa da matéria seca do sorgo seja um dos fatores que propiciam a maior incidência da doença no feijoeiro. As menores incidências de murcha-de-fusário ocorreram em sucessão ao milheto (7,02\%). Também corroborando os resultados obtidos por Toledo-Souza (2006), foi observado que menores incidências de murcha-de-fusário ocorreram quando o feijoeiro foi precedido por milheto (18\%), milheto e braquiária (17\%) e braquiária e milheto (média de $23 \%$ ), nas safras 2003, 2004 e 2005, respectivamente.

O rendimento de grãos do feijoeiro não foi influenciado, significativamente, pelos tratamentos com regulador de crescimento e fungicida biológico, assim como a interação destes com as palhadas das culturas de cobertura. No entanto, houve efeito significativo sobre este rendimento, nas culturas de cobertura do solo (Tabela 2).

Barbosa et al. (2008) concluíram que a utilização do regulador de crescimento Stimulate ${ }^{\circledR}$, sobre o feijoeiro cv. IPR Juriti, não proporcionou diferenças significativas nas variáveis analisadas (altura de inserção da primeira vagem, percentagem de vagens normais, número de vagens por planta, número de sementes por vagem, número de sementes por planta, massa de 100 sementes e produtividade), corroborando os resultados deste trabalho. No entanto, Cobucci et al. (2005), em três experimentos conduzidos na região de Unaí (MG), detectaram que o uso do bioestimulante Stimulate ${ }^{\circledR}$, aplicado nas fases fisiológicas R5 e R7, proporcionou aumento significativo na produtividade do feijoeiro, independentemente do cultivo utilizado (convencional ou direto). A produtividade média do feijoeiro, nos experimentos avaliados, variou de $2.148 \mathrm{~kg} \mathrm{ha}^{-1} \mathrm{a}$ $3.816 \mathrm{~kg} \mathrm{ha}^{-1}$.

A palhada do milheto favoreceu um maior rendimento de grãos do feijoeiro $\left(2.054 \mathrm{~kg} \mathrm{ha}^{-1}\right)$, diferindo somente da palhada do sorgo (1.254 $\left.\mathrm{kg} \mathrm{ha}^{-1}\right)$. Os resultados obtidos corroboram os de Silva (2006), que, estudando as mesmas culturas de cobertura, na mesma área, obteve maior produtividade do feijoeiro, na palhada de milheto, com $3.147 \mathrm{~kg} \mathrm{ha}^{-1}$, diferindo somente da palhada do sorgo, com $1.956 \mathrm{~kg} \mathrm{ha}^{-1}$, na safra 2004.

Silveira et al. (2005), utilizando as mesmas palhadas, na mesma área, obtiveram rendimento de grãos de $2.197 \mathrm{~kg} \mathrm{ha}^{-1}$, do feijoeiro cv. Pérola, na sucessão à palhada de milheto. Segundo Oliveira et al. (2002), o maior rendimento de grãos do feijoeiro, na palhada de milheto, pode, provavelmente, estar relacionado ao sistema radicular profundo e bastante ramificado, com alta capacidade de extração de nutrientes, desta espécie de cobertura. Salton \& Kichel (1998) citam que o alto conteúdo de potássio $\left(33,5 \mathrm{~g} \mathrm{~kg}^{-1}\right)$ no milheto, associado à sua elevada produção de massa de matéria seca, caracterizam esta espécie como altamente eficiente em reciclar potássio, sendo seu uso recomendado, neste sentido, principalmente para solos arenosos, onde este elemento é bastante lixiviado.

A produtividade média do feijoeiro comum cv. BRS Valente foi de $1.706 \mathrm{~kg} \mathrm{ha}^{-1}$, em solo que se encontrava no quinto ano sob SPD. Silveira et al. (2005), estudando as mesmas culturas de cobertura, na mesma área experimental, no entanto, no primeiro 
Tabela 2. Rendimento de grãos, número de vagens por planta, número de grãos por vagem, massa de 100 grãos, estande inicial e estande final do feijoeiro cv. BRS Valente, em sucessão a diferentes culturas de cobertura e tratado com regulador de crescimento (RC) e fungicida biológico (FB) (Santo Antônio de Goiás, GO, 2006).

\begin{tabular}{|c|c|c|c|c|c|c|}
\hline Tratamento & $\begin{array}{l}\text { Rendimento } \\
\left(\mathrm{kg} \mathrm{ha}^{-1}\right)\end{array}$ & $\begin{array}{c}\mathrm{N}^{\mathrm{o}} \text { vagens } \\
\text { planta }^{-1}\end{array}$ & $\begin{array}{c}\mathrm{N}^{o} \text { de grãos } \\
\text { vagem }^{-1}\end{array}$ & $\begin{array}{c}\text { Massa de } \\
100 \text { grãos }(\mathrm{g})\end{array}$ & $\begin{array}{l}\text { Estande inicial } \\
\left(\text { plantas } \mathrm{m}^{-2}\right)\end{array}$ & $\begin{array}{l}\text { Estande fina } \\
\left(\text { plantas } \mathrm{m}^{-2}\right)\end{array}$ \\
\hline \multicolumn{7}{|c|}{ Coberturas vegetais } \\
\hline Braquiária consorciada & $1.733^{*} \mathrm{ab}^{* *}$ & $11,2^{*} \mathrm{ab}$ & $3,9^{*}$, ns & $19,2^{*}$, ns & $15,7^{*}$, ns & $13,6^{*} \mathrm{~b}$ \\
\hline Braquiária solteira & $1.646 \mathrm{ab}$ & $11,9 \mathrm{a}$ & 3,8 & 19,7 & 17,0 & $12,7 \mathrm{~b}$ \\
\hline Milheto & $2.054 \mathrm{a}$ & $10,5 \mathrm{ab}$ & 3,9 & 20,1 & 16,8 & $15,0 \mathrm{ab}$ \\
\hline Mombaça & $1.809 \mathrm{ab}$ & $9,4 a b$ & 3,7 & 19,5 & 15,8 & $13,0 \mathrm{~b}$ \\
\hline Sorgo & $1.254 \mathrm{~b}$ & $8,1 \mathrm{ab}$ & 3,7 & 18,3 & 17,5 & $13,9 \mathrm{ab}$ \\
\hline Crotalária & $1.553 \mathrm{ab}$ & $9,1 \mathrm{ab}$ & 3,9 & 18,5 & 17,4 & $13,7 \mathrm{~b}$ \\
\hline Estilosantes & $1.681 \mathrm{ab}$ & $7,4 \mathrm{~b}$ & 3,8 & 20,1 & 17,0 & $15,0 \mathrm{ab}$ \\
\hline Guandu & $1.920 \mathrm{ab}$ & $8,8 \mathrm{ab}$ & 3,7 & 19,7 & 18,6 & $16,2 \mathrm{a}$ \\
\hline \multicolumn{7}{|c|}{ Fungicidas/regulador crescimento } \\
\hline Testemunha & 1.828 & 9,5 & 3,9 & 19,1 & 17,6 & 14,6 \\
\hline Regulador crescimento (RC) & 1.714 & 9,7 & 3,7 & 19,5 & 16,6 & 13,8 \\
\hline Fungicida biológico (FB) & 1.679 & 9,6 & 3,8 & 19,5 & 16,5 & 13,7 \\
\hline $\mathrm{RC}+\mathrm{FB}$ & 1.605 & 9,3 & 3,8 & 19,5 & 17,1 & 14,4 \\
\hline C.V.a $(\%)$ & 35,75 & 38,83 & 10,41 & 15,16 & 18,37 & 15,07 \\
\hline C.V.b $(\%)$ & 22,34 & 22,99 & 9,25 & 9,67 & 13,25 & 11,48 \\
\hline
\end{tabular}

* Dados originais; ** Letras maiúsculas e minúsculas iguais, na coluna, indicam que as médias não diferem entre si, pelo teste Tukey ( $\mathrm{p}>0,05)$; ${ }^{\text {ns }}$ Não significativo, pelo teste $\mathrm{F}$, a $5 \%$ de probabilidade.

ano no SPD, obtiveram, em média, $1.676 \mathrm{~kg} \mathrm{ha}^{-1} \mathrm{de}$ produtividade do feijoeiro comum cultivar Pérola. Observa-se que o plantio do feijoeiro, após cinco anos em SPD, se mantém com boa produtividade, diferenciando-se das culturas de cobertura.

Não houve efeito significativo para as variáveis número de vagens por planta, número de grãos por vagem, massa de 100 grãos, estande inicial e estande final, para o feijoeiro dos tratamentos com regulador de crescimento e fungicida biológico, assim como para a interação destes com as palhadas. Houve diferença significativa, quanto ao número de vagens por planta e estande final, para o feijoeiro em sucessão às culturas de cobertura do solo (Tabela 2).

O número de vagens por planta, no feijoeiro, foi maior em sucessão à braquiária solteira $(11,9)$, diferindo somente do estilosantes $(7,4)$. Kluthcouski et al. (2001) obtiveram, sobre a palhada da braquiária, valores médios de 11,98 vagens por planta.

Para Andrade et al. (1998), a não significância do número de grãos por vagem deve-se, provavelmente, a ser esta uma característica varietal pouco afetada pelo meio ambiente. Resultados semelhantes foram constatados por Silva (2006), que, trabalhando com as mesmas culturas de cobertura, não obteve diferenças significativas entre estas, quanto ao número de grãos por vagem, como observado nos dados obtidos neste trabalho.

Não houve diferenças significativas entre as culturas de cobertura, para massa de 100 grãos do feijoeiro (Tabela 2), corroborando os resultados encontrados por Silva (2006), que, em duas safras, utilizando a mesma cultivar, não obteve diferenças significativas, quanto à massa de 100 grãos do feijoeiro plantado sobre a palhada das mesmas culturas de cobertura utilizadas neste trabalho. De acordo com Silva et al. (2005), na cultura do feijão, a massa de 100 grãos é um atributo estreitamente mais relacionado com a cultivar utilizada do que com as práticas culturais adotadas, tais como o preparo do solo e sucessão de culturas, e, talvez, por isto, não tenha sido detectada influência das mesmas sobre a massa de 100 grãos.

$\mathrm{O}$ estande final do feijoeiro foi maior na sucessão ao guandu $(16,2)$, não diferindo do milheto, estilosantes e sorgo, e foi menor nas palhadas de braquiária solteira $(12,7)$, diferindo apenas do guandu (Tabela 2). A variação dos valores encontrados para estande do feijoeiro decorre, provavelmente, do volume da palhada das culturas, dificultando a operação de plantio, conforme relatado por Silveira et al. (2005).

\section{CONCLUSÕES}

1. A aplicação de fungicida biológico e regulador de crescimento, em tratamento de sementes, não influencia na severidade das podridões radiculares, incidência da murcha-de-fusário, rendimento de grãos, estande inicial e final e nos componentes da produtividade do feijoeiro. 
2. A palhada de sorgo favoreceu o aumento das podridões radiculares e da murcha-de-fusário do feijoeiro, causando menor rendimento de grãos.

3. O feijoeiro, em sucessão ao milheto, apresentou maior rendimento produtivo.

\section{REFERÊNCIAS}

ANDRADE, M. J. B. et al. Resposta da cultura do feijoeiro à aplicação foliar de molibdênio e às adubações nitrogenadas de plantio e cobertura. Ciência e Agrotecnologia, Lavras, v. 22, n. 2, p. 499-508, 1998.

BARBOSA, R. M. et al. Produção de sementes de feijoeiro em função da aplicação de bioestimulante e doses de ureia. In: CONGRESSO NACIONAL DE PESQUISA DE FEIJÃO, 9., Campinas. Anais... Campinas: IAC, 2008. p. $1535-1537$.

CASTRO, P. R. C.; CATO, S. C.; VIEIRA, E. L. Biorreguladores e bioestimulantes em feijoeiro. In: FANCELLI, A. L.; DOURADO-NETO, D. (Eds.). Feijão irrigado: tecnologia \& produção. Piracicaba: ESALQ, 2005. p. 54-62.

COBUCCI, T.; WRUCK, F. J.; SILVA, J. G. Resposta do feijoeiro (Phaseolus vulgaris L.) a aplicações de bioestimulante e complexos nutritivos. In: CONGRESSO NACIONAL DE PESQUISA DE FEIJÃO, 8., 2005, Goiânia. Resumos... Santo Antônio de Goiás: Embrapa Arroz e Feijão, 2005. p. 1078-1081.

COMPANHIA NACIONAL DE ABASTECIMENTO (Conab). Acompanhamento da safra brasileira: grãos: quinto levantamento, fevereiro/2009. 2009. Disponível em: <http://www.conab.gov.br>. Acesso em: 02 mar. 2009.

FARIA, A. Y. K.; ALBUQUERQUE, M. C. de F.; CASSETARI NETO, D. Qualidade fisiológica de sementes de algodoeiro submetidas a tratamentos químico e biológico. Revista Brasileira de Sementes, Pelotas, v. 25, n. 1, p. 121-127, 2003.

FERREIRA, D. F. Sistema de análise de variância para dados balanceados (Sisvar): versão 4.6 (Build 6.0) DEX/ UFLa. 2003. Disponível em: <http://www.dex.ufla.br/ danielff/prog.htm>. Acesso em: 10 ago. 2006.

GARCIA, R. N.; FORNASIERI FILHO, D.; ROSSATO JÚNIOR, J. A. de S. Influência de cultura de cobertura morta e nitrogênio sobre os componentes produtivos da cultura do feijoeiro de inverno em sucessão à cultura do milho. In: CONGRESSO BRASILEIRO DE CIÊNCIA DO SOLO, 29., 2003, Ribeirão Preto. Anais... Ribeirão Preto: Sociedade Brasileira de Ciência do Solo, 2003. 1 CD-ROM.
HINOJOSA, G. F. Auxina em plantas superiores: síntese e propriedades fisiológicas. In: CID, L. P. B. Hormônios vegetais em plantas superiores. Brasília, DF: Embrapa Recursos Genéticos e Biotecnologia, 2005. p. 15-57.

KLUTHCOUSKI, J. et al. Bean yield as affected by mulch from different crop residues. Annual Report of the Bean Improvement Cooperative, East Lansing, v. 44, n. 1, p. 69-70, 2001.

KLUTHCOUSKI, J.; AIDAR, H.; THUNG, M. Principais problemas da cultura do feijão no Brasil. In: FANCELLI, A. L.; DOURADO-NETO, D. (Eds.). Feijão: estratégias de manejo para alta produtividade. Piracicaba: ESALQ, 2007. p. 53-102.

LOBO JÚNIOR, M. et al. Efeito de rotações de culturas e do sistema de plantio sobre a severidade de podridões radiculares do feijoeiro comum em cultivo orgânico. In: CONGRESSO NACIONAL DE PESQUISA DE FEIJÃO, 8., Goiânia. Anais... Santo Antônio de Goiás: Embrapa Arroz e Feijão, 2005. p. 186-188.

MELO, I. S. Agentes microbianos de controle de fungos fitopatogênicos. In: MELO, I. S.; AZEVEDO, J. L. (Eds.). Controle biológico. Jaguariúna: Embrapa, 1998. p. 17-66.

MELO, I. S. de; FAULL, J. L. Parasitism of Rhizoctonia solani by strains of Trichoderma spp. Scientia Agricola, Piracicaba, v. 57, n. 1, p. 55-59, 2000.

MENEZES, L. A. S. Alterações de propriedades químicas do solo em função da fitomassa de plantas de cobertura. 2002. 73 f. Dissertação (Mestrado em Produção Vegetal)Escola de Agronomia e Engenharia de Alimentos, Universidade Federal de Goiás, Goiânia, 2002.

OLIVEIRA, T. K. de; CARVALHO, G. J. de; MORAES, R. N. S. Plantas de cobertura e seus efeitos sobre o feijoeiro em plantio direto. Pesquisa Agropecuária Brasileira, Brasília, DF, v. 37, n. 8, p. 1079-1087, 2002.

PAULA JÚNIOR, T. J. et al. White mold intensity on common bean in response to plant density, irrigation frequency, grass mulching, Trichoderma spp., and fungicide. Summa Phytopathologica, Botucatu, v. 35, n. 1, p. 44-48, 2009

RESENDE, M. de E. L. et al. Inoculação de sementes de milho utilizando o Trichoderma harzianum como promotor de crescimento. Ciência e Agrotecnologia, Lavras, v. 28, n. 4, p. 793-798, 2004.

SALTON, J. C.; KICHEL, A. N. Milheto: uma alternativa para cobertura do solo e alimentação animal. Revista Plantio Direto, Passo Fundo, v. 45, n. 1, p. 41-43, 1998.

SCHOONHOVEN, A. VAN; PASTOR-CORRALES, M. A. Sistema estándar para la evaluación de germoplasma de frijol. Cali: CIAT, 1987. 
SILVA, M. G. da. Impacto de sistemas agrícolas na produtividade do feijoeiro irrigado e na qualidade biológica do solo. 2006. 116 f. Tese (Doutorado em Produção Vegetal)-Escola de Agronomia e Engenharia de Alimentos, Universidade Federal de Goiás, Goiânia, 2006.

SILVA, M. G. da et al. Produtividade do feijoeiro de inverno em sistemas de produção irrigados. In: CONGRESSO NACIONAL DE PESQUISA DE FEIJÃO, 8., 2005, Goiânia. Resumos... Santo Antônio de Goiás: Embrapa Arroz e Feijão, 2005. p. 846-848.

SILVA, S. C. da; SANTANA, N. M. P. de; PELEGRINI, J. C. Informações meteorológicas para pesquisa e planejamento agrícola, referente ao Município de Santo Antônio de Goiás, GO, 2003. Santo Antônio de Goiás: Embrapa Arroz e Feijão, 2004. (Documentos, 163).

SILVEIRA, P. M. da et al. Adubação nitrogenada no feijoeiro cultivado sob plantio direto em sucessão de culturas. Pesquisa Agropecuária Brasileira, Brasília, DF, v. 40, n. 4, p. 377-381, 2005.
TOLEDO-SOUZA, E. D. de. Influência de sistemas de cultivo e de sucessões de culturas em patógenos de solo do feijoeiro-comum (Phaseolus vulgaris L.). 2006. $100 \mathrm{f}$. Tese (Doutorado em Fitopatologia)-Instituto de Ciências Biológicas, Departamento de Fitopatologia, Universidade de Brasília, Brasília, DF, 2006.

VIEIRA, E. L. Ação de bioestimulante na germinação de sementes, vigor de plântulas, crescimento radicular e produtividade de soja (Glicine max), feijoeiro (Phaseolus vulgaris L.) e arroz (Oryza sativa L.). 2001. 122 f. Tese (Doutorado em Fitotecnia)-Escola Superior de Agricultura Luiz de Queiroz, Universidade de São Paulo, Piracicaba, 2001.

VIEIRA, E. L.; CASTRO, P. R. C. Ação de bioestimulante na cultura da soja (Glycine max (L.) Merrill). Cosmópolis: Stoller do Brasil, 2004. 